scrub typhus due to mites should be included in the way they are among the diseases listed at the beginning of this whole section as controllable by DDT. Cockroaches, bed bugs and other troublesome creatures are dealt with in a chapter on pests.

Dr. Knipling, on veterinary applications, first recapitulates briefly the essentials of DDT toxicity to stock. Formulations are then compared, and special techniques for spraying and dipping are outlined and illustrated by numerous photographs throughout the text. There is some overlap inevitably with the medical field, but here is found the more extensive exposition of DDT in tick control, and for controlling various biting insects, blowflies, myiasis flies, lice, fleas, mites, exclusively or primarily of veterinary concern. Indications of insecticides more effective than DDT for certain arthropods are clearly set out.

What might well have been indicated clearly in the title or introduction to this book is that, although published in 1959, its subject-matter is not covered beyond 1954. The basic problems of toxicology being by then well clarified for DDT, this aspect is not greatly affected by the time lag. But DDT-resistance in some insects, notably houseflies, had compelled the use of alternative insecticides in some parts of the world well before 1954. This is, of course, brought out in the presentation of the medical section, and Dr. Simmons also focuses attention on the problem by concluding with a general appraisal of DDT-resistance, as it existed by 1954, with comment on possible prospects. Much newer work on DDT-resistance and on resistance to other contact insecticides is, inevitably, not embodied in this book. Provided this is borne in mind, this volume is undoubtedly notable, well-documented and a valuable compilation of the facts about the development of DDT for large-scale usage, its successes, its failures, and the early impacts of insecticide resistance on the new outlook which DDT had first made possible in medical and veterinary entomology. There is no index ; this may be intended at the end of the series. An introductory table of chapter content, further sub-titling and some crossreferences in the text, and the good quality of printing and illustration combine to make this a pleasing book to handle and consult.

D. S. Bertram

\section{INCENDIARIES, FIREWORKS AND FIREARMS}

\section{A History of Greek Fire and Gunpowder}

By Prof. J. R. Partington. Pp. xvi+381. (Cambridge: W. Heffer and Sons, Ltd., 1960.) 70s. net.

$\mathbf{T}^{\mathrm{N}}$ his new book Prof. Partington surveys the 1 history of incendiaries and gunpowder in the same thorough way that characterized his well-known "Origins and Development of Applied Chemistry". $\mathrm{He}$ has taken great care to inspect the original sources of information, and he quotes them at length in the seven fully annotated chapters of this book, which has been completed by good indexes and twenty-one illustrations, some of which are seldom reproduced.

The book opens with a discussion of the incendiaries used in ancient warfare, culminating in the 'Greek fire' which terrified the Crusaders and which was one of the props of the Byzantine Empire. Many of these ancient incendiaries contained one of the numerous types of crude oil found in Mesopotamia or the regions north of that country. The author believes that the basis of the earliest Greek fire was liquid rectified petroleum or volatile petrol, which was projected in hand-grenades, or ordinary petroleum in tubs shot from ballistae. The mixture of petrol and resinous substances, thickened into a jelly, and the mechanical means of projecting it constituted the invention of Greek fire, an achievement of chemical engineering.

In his second chapter the author turns to the examination of "The Book of Fires of Mark the Greek", which he compares with passages from Albertus Magnus's "De Mirabilibus Mundi" and Roger Bacon's "De secretis operibus artis", from which he concludes that there seems to be no reason. able doubt that Roger Bacon was well acquainted with the preparation and properties of gunpowder, though probably ignorant of its use as a propellent. $\mathrm{He}$ may have derived his knowledge about its composition from the "Liber Ignium", which is probably of Arabic origin.

The next chapter is devoted to the "Legend of Black Berthold", the imaginary German monk said to have invented gunpowder and cannon. The earliest picture of a cannon is found in an English document, its earliest mention in an Italian one of 1326. He then proceeds to discuss the earliest English, French, Burgundian, German and Italian cannon and their nomenclature. A further chapter discusses miscellaneous fifteenth-century treatises on military arts and their knowledge of the use of gunpowder and firearms, mines and rockets.

Chapters 5 and 6 are devoted to a systematic discussion of gunpowder and firearms in Muslim lands and in China. Here the author dispels many erroneous statements of earlier authors by carefully examining the original texts and consulting such experts as Holmyard and Needham. His conclusions are that saltpetre was known under the Sung dynasty (A.D. 960-1279), and that around 1044 certain 'protogunpowder' mixtures were used in bombs but not as propellents. About 1233 we find the prototype of a gun described in Chinese literature, and true gunpowder was known towards the end of the Mongol Yuan dynasty (A.D. 1260-1368), when it was also known in Europe. Though there is a possibility that gunpowder was discovered in China, we are not certain that cannon were invented in that country, as the information about cast-iron Chinese guns, said to date back to 1356 , is unsatisfactory. The Arabs seem to have introduced gunpowder from the East, first using it as an incendiary like Greek fire. Cannon and firearms seem to play a part from the fifteenth century onwards only in Ottoman warfare.

The last chapter is devoted to the history of saltpetre. Here the author could have consulted with profit M. Levey's essays on chemical technology in ancient Mesopotamia rather than the much older evidence he quotes; although his discussion of the classical and post-classical evidere of this most important ingredient of gunpowder is excellent and provides us with many useful data on the ancient manufacture of saltpetre.

Prof. Partington has again given us a handbook which not only the artillery expert and the chemist but also the historian of technology will consult with profit for many years to come. R. J. Forbes 